\title{
Catalytic Rearrangement of Xanthates to Dithiolcarbonates")
}

\author{
Toshinobu Kawata, Kazunobu Harano and Tanezo Taguchi \\ Faculty of Pharmaceutical Sciences, Kyushu University $\left.{ }^{2}\right)$
}

(Received October 2, 1972)

\begin{abstract}
During a research of the Friedel-Crafts reaction using xanthate, it was found that xanthates rearrange to dithiolcarbonates by the catalysis of aluminum chloride in carbon disulfide. This rearrangement needs at least a molar equivalent of aluminum chloride to xanthates and proceeds even at room temperature. With respect to solvent, carbon disulfide can be replaced by chloroform without essential effect on the product distribution. It was presumed from a study of crossover reaction that this rearrangement might have the nature of intermolecular reaction.
\end{abstract}

In comparison with ethyl carbonate as an alkylating agent in the Friedel-Crafts reaction, the use of ethyl S-ethyl xanthate(Ia) which is sulfur analogue of ethyl carbonate was considered. The reaction was carried out as follows: Ethyl S-ethyl xanthate(Ia) and benzene were dissolved in carbon disulfide and the solution was refluxed in the presence of aluminum chloride. As a result, ethyl dithiolcarbonate(Ib) was obtained in addition with ethylbenzene in a formation ratio 1.2:1.0. This suggested that general xanthate might rearrange to dithiolcarbonate by the catalysis of aluminum chloride in contrary to the Chugaev reaction. Accordingly, this study was undertaken to seek after the generality of the rearrangement.
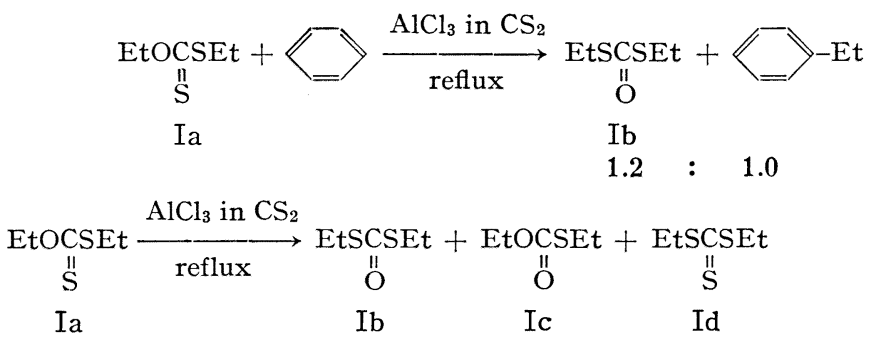

Chart 1

First, the effect of molar ratio of the xanthate(Ia) and aluminum chloride on the product formation was examined in the operation that the both reagents were refluxed in carbon disulfide for $40 \mathrm{~min}$. The gas chromatographic analyses showed the existence of ethyl dithiolcarbonate(Ib), ethyl thiolcarbonate(Ic) and ethyl trithiocarbonate(Id) in the reaction mass (Chart 1). As seen in Table I, when a molar equivalent of aluminum chloride to the xanthate (Ia) was used, the best result was obtained in the formation ratio of the dithiolcarbonate(Ib) to the other products(Ic and Id). Moreover, it was found useful for the yield-up of Ib to add aluminum chloride portionwise. On the other hand, when less and also larger amount of aluminum chloride were used, the formation ratio of $\mathrm{Ib}$ decreased.

The reaction was found to occur even at room temperature and in the usage of chloroform in place of carbon disulfide as solvent. The product distribution of the reaction in chloroform appeared to be approximately identical with that in carbon disulfide (Table II).

1) a) T. Taguchi, Rearrangement and trans Elimination contrary to the Chugaev Reaction Rule. X;

b) Part IX: K. Harano and T. Taguchi, Chem. Pharm. Bull. (Tokyo), 20, 2357 (1972).

2) Location: Katakasu, Fukuoka. 
TABLE I. Effect of Molar Ratio on Product Formation in the Reaction of Ethyl S-Ethyl Xanthate(Ia) with $\mathrm{AlCl}_{3}$ in Carbon Disulfide

\begin{tabular}{|c|c|c|c|c|c|}
\hline \multicolumn{2}{|c|}{ Molar ratio } & \multirow{2}{*}{$\begin{array}{c}\text { Reflux } \\
\text { time(min) }\end{array}$} & \multicolumn{3}{|c|}{ Formation ratio of products } \\
\hline \multicolumn{2}{|c|}{ EtOCSSEt(Ia) $: \mathrm{AlCl}_{3}$} & & EtSCOSEt( & $\cos E$ & $\operatorname{CSSEt}(\mathrm{Id})$ \\
\hline 1.0 & 0.5 & 40 & only $\left.{ }^{a}\right)$ & & \\
\hline 1.0 & 1.0 & 40 & 1.0 & 0.6 & 0.5 \\
\hline 1.0 & 2.0 & 40 & 1.0 & 0.8 & 1.2 \\
\hline 1.0 & $1.0^{b)}$ & 60 & 1.0 & 0.06 & 0.1 \\
\hline
\end{tabular}

a) But a considerable amount of Ia was recovered.

b) Aluminum chloride was added portionwise.

TABLE II. Effect of Solvent in the Reaction of $\mathrm{AlCl}_{3}$ with Ia at Room Temperature

\begin{tabular}{|c|c|c|c|c|c|c|c|c|}
\hline \multicolumn{2}{|c|}{ Molar ratio } & \multirow[b]{2}{*}{ Solvent } & \multirow{2}{*}{$\begin{array}{l}\text { Reaction } \\
\text { time(hr) }\end{array}$} & \multicolumn{5}{|c|}{ Products } \\
\hline Ia & $: \quad \mathrm{AlCl}_{3}$ & & & $\mathrm{Ib}$ & $:$ & Ic & $:$ & $\mathrm{Id}$ \\
\hline 1.0 & 1.5 & $\mathrm{CS}_{2}$ & 20 & 1.0 & & 0.6 & & 1.1 \\
\hline 1.0 & 1.5 & $\mathrm{CHCl}_{3}$ & 20 & 1.0 & & 0.5 & & 0.8 \\
\hline
\end{tabular}

TABLE III. Dithiolcarbonates derived from Reaction of Xanthates with a Molar Equivalent of $\mathrm{AlCl}_{3}$ in Carbon Disulfide

$$
\underset{\mathrm{S}}{\mathrm{ROCSR}} \longrightarrow \underset{\mathrm{O}}{\mathrm{RSCSR}}
$$

\begin{tabular}{|c|c|c|c|c|c|c|c|c|c|c|c|c|}
\hline \multirow[b]{3}{*}{$\mathrm{R}$} & \multirow[b]{3}{*}{$\mathrm{R}^{\prime}$} & \multirow{2}{*}{\multicolumn{2}{|c|}{$\begin{array}{l}\text { Reaction } \\
\text { time(hr) }\end{array}$}} & \multirow{3}{*}{$\begin{array}{l}\text { Yield } \\
\text { (\%) }\end{array}$} & \multirow{2}{*}{\multicolumn{2}{|c|}{$\mathrm{IRcm}^{-1 b)}$}} & \multirow{3}{*}{$\begin{array}{c}\mathrm{bp} \\
{ }^{\circ} \mathrm{C} / \mathrm{mmHg}\end{array}$} & \multirow{3}{*}{ Formula } & \multicolumn{4}{|c|}{ Analysis $(\%)$} \\
\hline & & & & & & & & & \multicolumn{2}{|c|}{ Calcd. } & \multicolumn{2}{|c|}{ Found } \\
\hline & & & & & $v_{c=0}$ & $v_{c-s}$ & & & $\mathrm{C}$ & $\mathrm{H}$ & $\overparen{C}$ & $\mathrm{H}$ \\
\hline $\mathrm{Me}$ & $\mathrm{Me}(\mathrm{IVb})$ & $\begin{array}{l}1 \\
1.5\end{array}$ & $\begin{array}{l}\mathrm{A} \\
\mathrm{B}\end{array}$ & $\begin{array}{l}68 \\
76\end{array}$ & 1647 & 870 & $167-168$ & $\mathrm{C}_{3} \mathrm{H}_{6} \mathrm{OS}_{2}$ & 29.48 & 4.95 & 29.43 & 4.90 \\
\hline Et & $\mathrm{Me}(\mathrm{Vb})$ & $\begin{array}{l}1 \\
1.5\end{array}$ & $\begin{array}{l}\mathrm{A} \\
\mathrm{B}\end{array}$ & $\begin{array}{l}55 \\
65\end{array}$ & 1647 & 869 & $83-85 / 30$ & $\mathrm{C}_{4} \mathrm{H}_{8} \mathrm{OS}_{2}$ & 35.27 & 5.92 & 35.07 & 6.05 \\
\hline Et & $\mathrm{Et}(\mathrm{Ib})$ & $\begin{array}{l}1 \\
1\end{array}$ & $\begin{array}{l}\mathrm{A} \\
\mathrm{B}\end{array}$ & $\begin{array}{l}45 \\
67\end{array}$ & 1645 & 870 & $83-86 / 14$ & $\mathrm{C}_{5} \mathrm{H}_{10} \mathrm{OS}_{2}$ & 39.97 & 6.71 & 39.86 & 6.77 \\
\hline$n-\operatorname{Pr}$ & $\mathrm{Me}^{c j}$ & $\begin{array}{l}1 \\
1.3\end{array}$ & $\begin{array}{l}\mathrm{A} \\
\mathrm{B}\end{array}$ & $\begin{array}{l}52 \\
55\end{array}$ & 1645 & 870 & $92-94 / 22$ & $\mathrm{C}_{5} \mathrm{H}_{10} \mathrm{OS}_{2}$ & 39.97 & 6.71 & 40.08 & 6.78 \\
\hline iso- $\mathrm{Pr}$ & $\mathrm{Me}^{d)}$ & 1 & A & 44 & 1642 & 863 & $79-82 / 19$ & $\mathrm{C}_{5} \mathrm{H}_{10} \mathrm{OS}_{2}$ & 39.97 & 6.71 & 40.33 & 6.64 \\
\hline$n-\mathrm{Bu}$ & $\mathrm{Me}$ & 1.5 & $\mathrm{~B}$ & 79 & 1645 & 866 & $96-97 / 2$ & $\mathrm{C}_{6} \mathrm{H}_{12} \mathrm{OS}_{2}$ & 43.87 & 7.36 & 43.75 & 7.37 \\
\hline $\mathrm{C}_{6} \mathrm{H}_{5} \mathrm{CH}_{2}$ & $\mathrm{Me}$ & $\begin{array}{l}1 \\
1\end{array}$ & $\begin{array}{l}\mathrm{A} \\
\mathrm{A}\end{array}$ & $\begin{array}{l}31^{e)} \\
78^{f)}\end{array}$ & 1643 & 867 & $110-111 / 1$ & $\mathrm{C}_{9} \mathrm{H}_{10} \mathrm{OS}_{2}$ & 54.51 & 5.08 & 54.50 & 5.22 \\
\hline cyclo- $\mathrm{C}_{6} \mathrm{H}_{11}$ & $\mathrm{Me}$ & 1 & A & 35 & 1644 & 864 & $145-147 / 17$ & $\mathrm{C}_{8} \mathrm{H}_{14} \mathrm{OS}_{2}$ & 50.49 & 7.41 & 50.65 & 7.52 \\
\hline $\mathrm{CH}_{3}\left(\mathrm{CH}_{2}\right)_{8} \mathrm{CH}_{2}$ & $\mathrm{Me}$ & 2.3 & B & 80 & 1647 & 869 & $138-140 / 1.8$ & $\mathrm{C}_{12} \mathrm{H}_{24} \mathrm{OS}_{2}$ & 58.01 & 9.74 & 58.37 & 10.00 \\
\hline $\mathrm{CH}_{3}\left(\mathrm{CH}_{2}\right)_{10} \mathrm{CH}_{2}$ & $\mathrm{Me}$ & 2.7 & $\mathrm{~B}$ & 75 & 1649 & 869 & $152-154 / 1.6$ & $\mathrm{C}_{14} \mathrm{H}_{28} \mathrm{OS}_{2}$ & 60.81 & 10.21 & 60.83 & 10.50 \\
\hline $\mathrm{CH}_{3}\left(\mathrm{CH}_{2}\right)_{12} \mathrm{CH}_{2}$ & $\mathrm{Me}$ & 2.7 & B & 75 & 1648 & 869 & $174-176 / 1.8$ & $\mathrm{C}_{16} \mathrm{H}_{32} \mathrm{OS}_{2}$ & 63.10 & 10.59 & 62.83 & 10.71 \\
\hline $\mathrm{CH}_{3}\left(\mathrm{CH}_{2}\right)_{14} \mathrm{CH}_{2}$ & $\mathrm{Me}$ & 1.5 & $\mathrm{~B}$ & 58 & 1649 & $875 \mathrm{n}$ & $\left.\mathrm{mp} 30-31.5^{\circ} \mathrm{C}^{g}\right)$ & $\mathrm{C}_{18} \mathrm{H}_{36} \mathrm{OS}_{2}$ & 65.00 & 10.91 & 65.05 & 11.00 \\
\hline
\end{tabular}

a) A: To a solution of xanthate was added $\mathrm{AlCl}_{3}$ all together and refluxed. $\mathrm{B}$ : To a solution of xanthate was added $\mathrm{AlCl}_{3}$ portionwise while refluxing.

b) in liquid film

c) NMR $\delta_{\mathrm{ppm}}^{\mathrm{ccl}:} 1.00(3 \mathrm{H}$, triplet, $J=7.4 \mathrm{~Hz}), 1.61(2 \mathrm{H}$, triple quartet $), 2.39(3 \mathrm{H}$, singlet $), 2.95(2 \mathrm{H}$, triplet, $J=6.8 \mathrm{~Hz})$

d) NMR $\delta_{\mathrm{ppm}}^{\mathrm{ccl}}$ : $1.36(6 \mathrm{H}$, doublet, $J=6.8 \mathrm{~Hz}), 2.40(3 \mathrm{H}$, singlet $), 3.75(1 \mathrm{H}$, heptuplet, $J=6.8 \mathrm{~Hz})$

e) prepared from benzyl S-methyl xanthate (IIIa).

f) prepared from methyl S-benzyl xanthate (IIa)

g) recrystallized from EtOH. 
This suggests that carbon disulfide used as solvent does not participate in the formation of ethyl trithiocarbonate(Id). Moreover, it was denied that the by-products, Ic and Id, might be formed through the decomposition of $\mathrm{Ib}$ which had been already formed, because the treatment of $\mathrm{Ib}$ with aluminum chloride resulted in the recovery of Ib without the formation of Ic and Id.

Thus, as the outline of the reaction was made clear, a large number of xanthates were synthesized and treated with a molar equivalent of aluminum chloride in carbon disulfide by two methods (See Table III). Table III tells us the following tendency of the reaction: 1 ) The xanthate in which $\mathrm{R}$ is primary alkyl is superior to secondary alkyl in yield of the rearrangement product. 2) Isomerization of $n$-propyl as an ester component to isopropyl was not found on this treatment, though it has been often observed in the Friedel-Crafts reaction. 3) In the formation of rearrangement product, methyl S-benzyl xanthate(IIa) prefers to its isomer, benzyl S-methyl xanthate(IIIa). 4) Xanthates which contain O-higher alkyl also rearrange to the corresponding dithiolcarbonates in good yields.

Next, to make clear whether the rearrangement reaction is intermolecular or intramolecular, a mixture of ethyl S-ethyl xanthate(Ia) and methyl S-methyl xanthate(IVa) was treated with aluminum chloride. The reaction gave ethyl methyl dithiolcarbonate $(\mathrm{Vb})$ which should be formed through a crossover reaction besides ethyl and methyl dithiolcarbonates (Ib and $\mathrm{IVb})$. This observation suggests that the nature of the rearrangement reaction may be ionic and intermolecular (Chart 2).

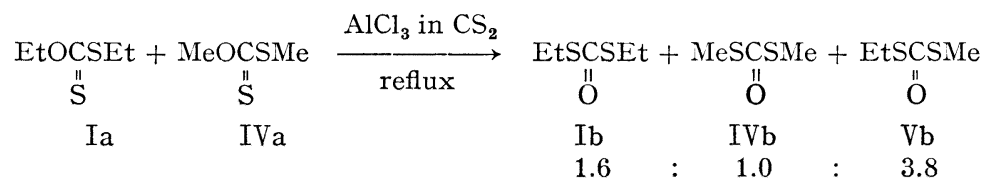

Chart 2

With respect to studies which treated the rearrangement of thionic ester to thiolic ester by the catalysis of Lewis acid, reports of two kinds have been published so far as we know. One is the rearrangement of thionocarbamates(VI) to thiolcarbamates (VIII) catalyzed by either $\mathrm{BF}_{3}$.ether or toluenesulfonic $\mathrm{acid}^{3)}$ and the other is that of thionobenzoates(IX) to thiolbenzoates(XI) catalyzed by $\mathrm{BF}_{3}$.ether used in a large quantity ${ }^{4}$ (Chart 3 ). However, to the best of my knowledge, there has been no report which aluminum chloride is used in a reaction of this kind, particularly in the reaction of xanthate. It is incomprehensible enough

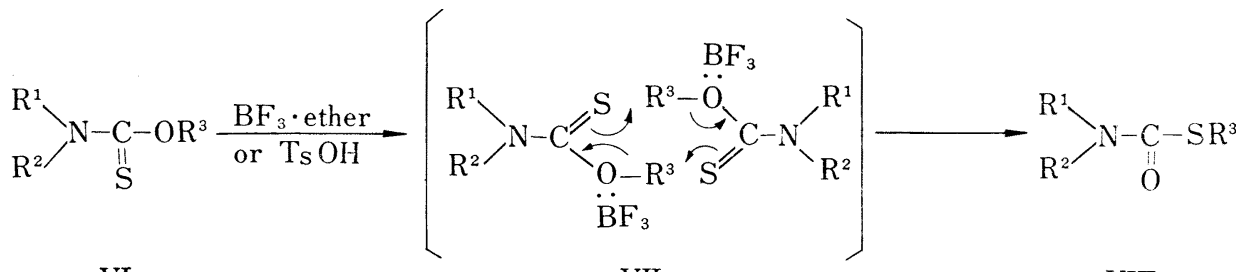

VI

VII

VIII

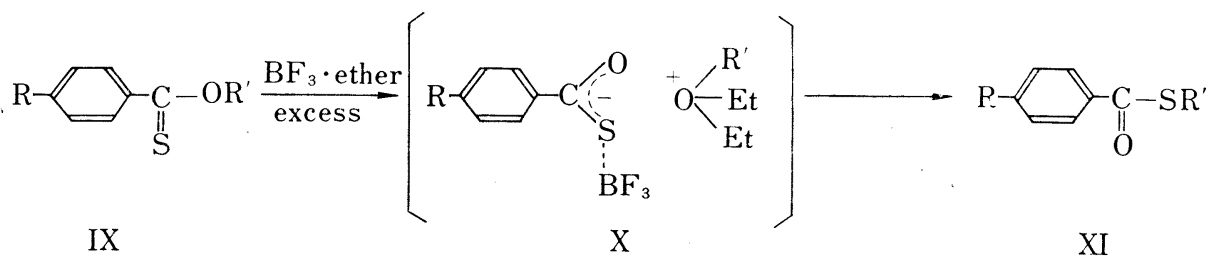

Chart 3 
that such an usual trial has not been reported. The reason why no report has been found may be probably due to unsuccess which was brought by the use of aluminum chloride in less quantity than a molar equivalent which is essential for this rearrangement reaction.

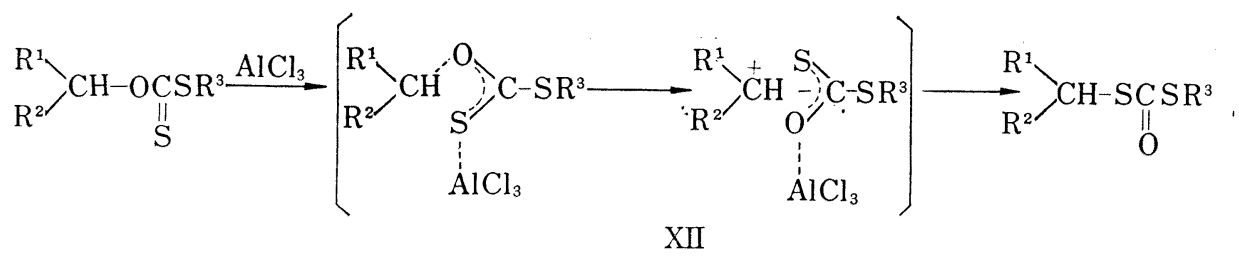

Chart 4

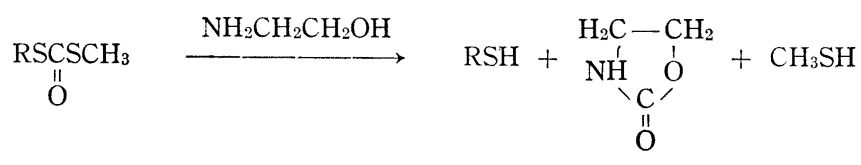

Chart $\tilde{5}$

It has been explained by the two research groups ${ }^{3,4)}$ that the catalytic rearrangements of thionocarbamates and thionobenzoates above-mentioned proceed through transition states VII and X respectively(Chart 3). On the other hand, as stated before, the rearrangement treated in this paper appears to be an intermolecular ionic reaction. Thus, the mechanism of the rearrangement may be presumed in the following way: Aluminum chloride coordinates to sulfur atom of the thiocarbonyl group and consequently C-O bond releases to produce a carbonium ion(XII) through which the rearrangement takes place intermolecularly (Chart 4). However, the reliability of the presumption must be confirmed by a further study which will follow this report. As reported previously, it was found that dithiolcarbonates can be easily introduced to mercaptans by boiling with 2 -aminoethanol ${ }^{5}$ ) (Chart 5). Accordingly, this procedure developed for introduction of xanthates to dithiolcarbonates came to have significance also as an intermediate reaction for the preparation of mercaptan from alcohol.

\section{Experimental}

All melting and boiling points were uncorrected. Infrared (IR) spectra were recorded with a JASCO DS-701G spectrometer. Nuclear magnetic resonance (NMR) spectra were obtained with a Nihon Denshi $\mathrm{C}-60 \mathrm{H}$ spectrometer at $60 \mathrm{MHz}$ using TMS as an internal standard. Gas chromatographic analyses were performed with a Shimadzu GC-4A gas chromatograph with a hydrogen flame ionization detector using a $5 \%$ SE-30 on Chamelite CK $(60-80$ mesh, $4 \mathrm{~m} \times 3 \mathrm{~mm})$ column.

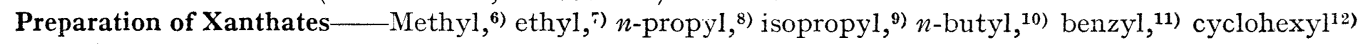
and cetyl ${ }^{13)}$ S-methyl xanthates were prepared by the known methods.

\footnotetext{
3) I. Kinoshita, S. Uchiumi, S. Chokai and Y. Oshima, Agr. Biol. Chem., 30, 710 (1966).

4) T. Oishi, M. Mori and Y. Ban, Tetrahedron Letters, 1971, 1777.

5) T. Taguchi, Y. Kiyoshima, O. Komori and M. Mori, Tetrahedron Letters, 1969, 3631.

6) F. Salomon, J. prakt. Chem., [2] 8, 117 (1873).

7) H.S. Fry, J. Am. Chem. Soc., 28, 796 (1906).

8) M. Delépine, Bull. soc. chem. France, 7, 404 (1910).

9) E. Wertheim, J. Am. Chem. Soc., 53, 4037 (1931).

10) G.W. Kenner and H. G. Khorana, J. Chem. Soc., 1952, 2076.

11) S.S. Nametkin and D. Kurssanow, J. Prakt. Chem., 112, 164 (1926).

12) T. Taguchi and M. Nakao, Tetrahedron, 18, 245 (1962).

13) D.L. Vincent and C.B. Purves, Can. J. Chem., 34, 1302 (1956).
} 
Ethyl S-ethyl xanthate ${ }^{14)}$ and methyl S-benzyl xanthate ${ }^{15)}$ were also prepared according to the literatures. Decyl, lauryl and myristyl S-methyl xanthates were prepared in application of the general synthetic method of xanthates ${ }^{12}$ ) (See Table IV).

Catalytic Rearrangement of Xanthates to Dithiolcarbonates with Aluminum Chloride. General MethodTo a solution of xanthates dissolved in carbon disulfide was added a molar equivalent of $\mathrm{AlCl}_{3}$ while refluxing either all together (Method A) or portionwise (Method B). After refluxing for $60-100$ min, ice-water was cautiously poured into the flask with shaking and the mixture was extracted with ether. The ether layer was washed with water, dried over anhydrous $\mathrm{MgSO}_{4}$ and evaporated to dryness. The residue (dithiolcarbonate) was purified by distillation or recrystallization. Yields and physical properties of dithiolcarbonates were listed in Table III.

TABLE IV. Alkyl S-Methyl Xanthate, $\mathrm{ROC}(=\mathrm{S}) \mathrm{SCH}_{3}$

\begin{tabular}{|c|c|c|c|c|c|c|c|c|c|}
\hline \multirow{3}{*}{$\mathrm{R}$} & \multirow{3}{*}{$\begin{array}{c}\text { Yield } \\
(\%)\end{array}$} & \multicolumn{2}{|c|}{$\left.\mathrm{IRcm}^{-1} a\right)$} & \multirow[t]{2}{*}{$\mathrm{bp}$} & \multirow{3}{*}{ Formula } & \multicolumn{4}{|c|}{ Analysis (\%) } \\
\hline & & & & & & \multicolumn{2}{|c|}{ Calcd. } & \multicolumn{2}{|c|}{ Found } \\
\hline & & $v_{c-o}$ & $v_{c=s}$ & ${ }^{\circ} \mathrm{C} / \mathrm{mmHg}$ & & $\mathrm{C}$ & $\mathrm{H}$ & $\mathrm{C}$ & $\mathrm{H}$ \\
\hline $\mathrm{CH}_{3}\left(\mathrm{CH}_{2}\right)_{8} \mathrm{CH}_{2}$ & 78 & 1221 & 1061 & $143-145 / 2.8$ & $\mathrm{C}_{12} \mathrm{H}_{24} \mathrm{OS}_{2}$ & 58.01 & 9.74 & 57.99 & 9.60 \\
\hline $\mathrm{CH}_{3}\left(\mathrm{CH}_{2}\right)_{10} \mathrm{CH}_{2}$ & 81 & 1220 & 1061 & $158-160 / 2$ & $\mathrm{C}_{14} \mathrm{H}_{28} \mathrm{OS}_{2}$ & 60.81 & 10.21 & 60.53 & 10.24 \\
\hline $\mathrm{CH}_{3}\left(\mathrm{CH}_{2}\right)_{12} \mathrm{CH}_{2}$ & 92 & 1220 & 1062 & $170-171 / 1.5$ & $\mathrm{C}_{16} \mathrm{H}_{32} \mathrm{OS}_{2}$ & 63.10 & 10.59 & 62.89 & 10.69 \\
\hline
\end{tabular}

a) in liquid film

Crossover Reaction-An equimolar mixture of ethyl S-ethyl xanthate (Ia) and methyl S-methyl xanthate (IVa) was refluxed with two molar equivalents of $\mathrm{AlCl}_{3}$ in carbon disulfide for $1 \mathrm{hr}$ and theresulting products were analyzed by gas chromatography. The chromatogram showed that ethyl methyl dithiolcarbonate (Va) was produced besides ethyl and methyl dithiolcarbonates (Ib and IVb), in a formation. ratio $3.8: 1.6: 1.0$.

Acknowledgement The authors are indebted to the staff of the analysis room of this faculty for elemental analyses and measurements of IR and NMR spectra.

14) F. Salomon, J. Prakt. Chem., [2] 6, 445 (1872).

15) H. Yoshida and S. Inokawa, Nippon Kagaku Zasshi, 86, 950 (1965). 